\title{
Severe Amlodipine Toxicity: A Case Rescued with Extracorporeal Membrane Oxygenation
}

\author{
Anand Sutar ${ }^{1}$, Pradeep M Venkategowda², Ashwini Murthy ${ }^{3}$, Srinivas Budanur Chikkaswamy ${ }^{4}$
}

\begin{abstract}
Amlodipine is a widely prescribed drugs for the management of hypertension. Its toxicity is associated with severe myocardial depression and refractory hypotension. We present a case of a 28-year-old female known case of seizure disorder and depression who got admitted to our hospital with a history of consumption of 80 tablets of $5 \mathrm{mg}$ amlodipine (total $400 \mathrm{mg}$ ). Patient presented to our hospital after $23 \mathrm{hours} \mathrm{following}$ consumption of the drug. Patient was managed in the intensive care unit (ICU) with mechanical ventilation support and intravenous infusion of noradrenalin, adrenalin, insulin-dextrose, and calcium gluconate. Due to refractory hypotension, venoarterial extracorporeal membrane oxygenation (VA-ECMO) was initiated on the same day. Patient was successfully managed and discharged home on the 8th day. This report highlights a rare case of a massive amlodipine overdose $(400 \mathrm{mg})$ and ECMO as a rescue therapy.

Keywords: Amlodipine, Extracorporeal membrane oxygenation, Hypotension, Insulin.

Indian Journal of Critical Care Medicine (2020): 10.5005/jp-journals-10071-23423
\end{abstract}

\section{INTRODUCTION}

Calcium channel blockers (CCBs) are the favorite drugs used for the management of hypertension, angina, and supraventricular tachyarrhythmias. Among the cardiovascular drug overdose ${ }^{1}$ reported to the toxic exposure surveillance system, ${ }^{2} \mathrm{CCBs}$ are common. Amlodipine, the long-acting (30-58 hours) drug belonging to the dihydropyridine group of CCBs is the commonly prescribed drug. The refractory bradycardia and hypotension associated with its overdose is very challenging to treat. This report highlights the rarest case of severe amlodipine toxicity (400 mg) managed with extracorporeal membrane oxygenation (ECMO).

\section{Case Description}

A 28-year-old female known case of seizure disorder and depression got admitted to our hospital with a history of consumption of about 80 tablets of amlodipine (5 mg each) at her residence. Patient's father noticed it initially as she was complaining giddiness and vomiting (30-45 minutes later) and immediately she was rushed to the local hospital. Nasogastric tube was placed and stomach wash was given with $50 \mathrm{~g}$ of activated charcoal hydrated with adequate intravenous fluids and started on noradrenalin and adrenalin in view of hypotension and later referred to our hospital for further management. Patient came to our hospital 23 hours after consumption of the drug. In the emergency room, the patient was conscious, afebrile, with a pulse rate of 120 beats/ minute, blood pressure $88 / 48 \mathrm{~mm} \mathrm{Hg}$, and $\mathrm{SpO}_{2}-96 \%$ (room air). Systemic examination showed bilateral crepitation on auscultation of lungs. Routine blood test showed $\mathrm{Hb} \% 11.3 \mathrm{~g} / \mathrm{dL}$, total leukocyte count 9,100 , platelet count 1.52 lakh cells/cu mm; serum sodium $132 \mathrm{meq} / \mathrm{L}$, potassium $-3.8 \mathrm{meq} / \mathrm{L}$, chloride $-104 \mathrm{meq} / \mathrm{L}$; serum creatinine $0.7 \mathrm{mg} / \mathrm{dL}$, blood urea: $18 \mathrm{mg} / \mathrm{dL}$, total bilirubin $0.5 \mathrm{mg} /$ $\mathrm{dL}$, SGOT -32 U/L, SGPT $28 \mathrm{U} / \mathrm{L}$, serum albumin $3.4 \mathrm{~g} / \mathrm{L}$; and arterial blood gas analysis $\mathrm{pH}: 7.42, \mathrm{pCO}_{2}: 28, \mathrm{pO}_{2}$ : 99 , and $\mathrm{HCO}_{3}$ : 15.6. The $2 \mathrm{D}$ transthoracic echocardiography showed global hypokinesia of left ventricle with ejection fraction of $25 \%$, chest X-ray showed bilateral minimal paracardiac haziness (pulmonary edema), and

\footnotetext{
${ }^{1-3}$ Department of Critical Care Medicine, Apollo Hospital, Sheshadripuram, Bengaluru, Karnataka, India

${ }^{4}$ Department of Cardiology, Apollo Multi-speciality Hospital,
} Bengaluru, Karnataka, India

Corresponding Author: Pradeep M Venkategowda, Department of Critical Care Medicine, Apollo Hospital, Sheshadripuram, Bengaluru, Karnataka, India, Phone: +918897575704, e-mail: drpradeepmarur@ gmail.com

How to cite this article: Sutar A, Venkategowda PM, Murthy A, Chikkaswamy SB. Severe Amlodipine Toxicity: A Case Rescued with Extracorporeal Membrane Oxygenation. Indian J Crit Care Med 2020;24(5):365-366.

Source of support: Nil

Conflict of interest: None

electrocardiograph showed sinus tachycardia. Patient was shifted to ICU for further management. Intravenous glucagon $5 \mathrm{mg}$ bolus was given and another $5 \mathrm{mg}$ repeated after 5 minutes. Insulin-dextrose infusion (0.5 IU/ kg/hour) and calcium gluconate infusion $(30 \mathrm{~mL} /$ hour) was also started. After an hour, her blood pressure dropped to $76 / 50 \mathrm{~mm} \mathrm{Hg}$ and she was very drowsy and tachypneic. Doses of noradrenalin and adrenalin were increased and she was intubated and mechanically ventilated. Due to refractory hypotension, VA-ECMO was planned as the rescue therapy. Right femoral vein was cannulated with $25 \mathrm{Fr}$ cannula and placed up to the junction of inferior venacava and right atrium. Left femoral artery was cannulated with $17 \mathrm{Fr}$ cannula and passed up to the abdominal aorta and an additional $7 \mathrm{Fr}$ cannula was used for distal perfusion. Pump flow was maintained at $4.5 \mathrm{~L} /$ minute, sweep gas flow of 800 $\mathrm{mL} /$ minute, $\mathrm{FIO} 2$ of 0.9 and activated clotting time of $180-200$ seconds. The ECMO was gradually weaned from 3rd day onward as the blood pressure started improving. Insulin-dextrose and calcium gluconate infusion gradually stopped after 72 hours. Patient was extubated on the 4th day following ECMO decannulation. Patient was shifted to the ward and later discharged home on the 8th day.

() The Author(s). 2020 Open Access This article is distributed under the terms of the Creative Commons Attribution 4.0 International License (https://creativecommons. org/licenses/by-nc/4.0/), which permits unrestricted use, distribution, and non-commercial reproduction in any medium, provided you give appropriate credit to the original author(s) and the source, provide a link to the Creative Commons license, and indicate if changes were made. The Creative Commons Public Domain Dedication waiver (http://creativecommons.org/publicdomain/zero/1.0/) applies to the data made available in this article, unless otherwise stated. 


\section{Discussion}

The CCBs are used for the treatment of essential hypertension, angina pectoris, arrhythmias, congestive heart failure, subarachnoid hemorrhage, migraine headache, and Raynaud's syndrome. These drugs act by blocking the voltage-sensitive (L-type) calcium channels ${ }^{3}$ and thus affects vascular smooth muscle tone, myocardial contractility, automaticity, and atrioventricular conduction. Amlodipine, belongs to dihydropyridine group of CCBs. In the usual dose (10-20 mg/day), this group of drugs has greater affinity for smooth muscle than the myocardium, ${ }^{4}$ whereas this selective affinity is lost in case of severe toxicity. ${ }^{5}$ Amlodipine toxicity (5-10 times the therapeutic dose) is seen within $0.5-1$ hour following consumption ${ }^{6}$ and its effect last for 30-58 hours (long duration) compared to other generation of dihydropyridines. Toxic manifestations include myocardial depression, lethargy, syncope, hypotension, nausea, vomiting, metabolic acidosis, hyperglycemia, altered mental status, dizziness, seizures, renal failure, and noncardiogenic pulmonary edema. ${ }^{7}$

Noncardiogenic pulmonary edema is secondary to precapillary vasodilatation. Renal failure is due to hypoperfusion. Metabolic acidosis is due to renal failure, prolonged hypotension, decreased insulin secretion and insulin resistance, and decreased mitochondrial activity.

Treatment is usually supportive maintenance of airway breathing and circulation. Gastrointestinal decontamination, though the evidence is lacking but still recommended due to severe toxicity and absence of specific antidote. ${ }^{8}$ Gastric lavage is beneficial (polyethylene glycol and activated charcoal $1 \mathrm{~g} / \mathrm{kg}$ ) if done within 1-2 hours of ingestion. Whole bowel irrigation is another option when extended release preparation is used. ${ }^{9}$

Atropine is used in case of symptomatic bradycardia. Transvenous pacing in patients with severe symptomatic bradycardia not responding to atropine or isoprenaline infusion. ${ }^{8}$ Hypotension is the major concern, which is initially managed with intravenous fluids. Once the patient is adequately hydrated, then inotropes can be added (dopamine, noradrenalin, and adrenalin).

Calcium chloride/gluconate helps to overcome the competitive blockade of calcium channels. It improves hypotension, contractility, and conduction abnormalities. Continuous intravenous infusion of calcium chloride $20-40 \mathrm{mg} / \mathrm{kg} / \mathrm{hour}(0.2-0.4 \mathrm{~mL} / \mathrm{kg} / \mathrm{hour}$ ) or boluses ( $10 \mathrm{~mL}$ of $10 \%$ calcium chloride/20 $-30 \mathrm{~mL}$ of calcium gluconate every 15-20 minutes, maximum $30 \mathrm{~g}$ over 12 hours). Glucagon (5-10 mg intravenous) ${ }^{6}$ stimulates adenylate cyclase and increases intracellular cyclic adenosine monophosphate (cAMP). This improves cardiac contractility and heart rate. Insulin ( $0.5 \mathrm{IU} / \mathrm{kg} /$ hour $)$ and $25 \%$ dextrose infusion at $25 \mathrm{~mL} /$ hour (hyperinsulinemic-euglycemia) ${ }^{10}$ help in increasing ionized calcium levels, hyperglycemic acidosis state, and increased cardiac. Hemodialysis is not used since these drugs are highly protein bound, require large volume of distribution $(21 \mathrm{~L} / \mathrm{kg})$ and have rapid metabolism.

Cardiac pacing, intra-aortic balloon pump, ECMO, ${ }^{11}$ therapeutic plasma exchange, ${ }^{12}$ and partial liquid ventilation are also used. ${ }^{6}$ Daubin et al. have used ECMO in a series of 17 patients within 6-7 hours of admission for the average duration of 74 hours. ${ }^{13}$ All patients showed in improvement in hemodynamics following initiation and the reduce the dose of vasopressors was reduced. Weinberg et al. ${ }^{14}$ used ECMO in two patients with amlodipine poisoning having refractory vasodilatory shock. Vignesh et al. ${ }^{15}$ used ECMO for successful outcome in three patients with antihypertensive drug overdose.
The mortality related to CCB overdose in cardiovascular medicine is around $48 \% .{ }^{16}$ Although the management of amlodipine is challenging, the early and aggressive treatments can improve outcome.

\section{ACKNOWLedgments}

We acknowledge intensivists, general physicians, cardiac surgeons, cardiac anesthetists, cardiologists, perfusionists, respiratory therapists, nurses, and management of the hospital for their valuable support.

\section{References}

1. Adams BD, Browne WT. Amlodipine overdose causes prolonged calcium channel blocker toxicity. Am J Emerg Med 1998;16(5): 527-528. DOI: 10.1016/S0735-6757(98)90011-0.

2. Litovitz TL, Klein-Schwartz W, Dyer KS, Shannon M, Lee S, Powers M. 1997 Annual report of the American Association of Poison Control Centers toxic exposure surveillance system. Am J Emerg Med 1998;16(5):443-497. DOI: 10.1016/S0735-6757(98)90000-6.

3. Ferrari R. Major differences among the three classes of calcium antagonists. Eur Heart J 1997;18(Suppl A):56-70. DOI: 10.1093/ eurheartj/18.suppl_A.56.

4. Russel RP. Side effects of calcium channel blockers. Hypertension 1988;11(3 Pt 2):I|42-I|44. DOI: 10.1161/01.HYP.11.3_Pt_2.II42.

5. Humbert Jr VH, Munn NJ, Hawkins RF. Noncardiogenic pulmonary edema complicating massive diltiazem overdose. Chest 1991;99(1):258-259. DOI: 10.1378/chest.99.1.258.

6. Saravu K, Balasubramanian R. Near-fatal Amlodipine poisoning. J Assoc Physicians India 2004;52:156-157.

7. Kerns W, Kline J, Ford M. Beta blocker and calcium channel blocker toxicity. Emerg Med Clin North Am 1994;12(2):365-383.

8. Kenny J. Treating overdose with calcium channel blockers. BMJ 1994;308(6935):992-993. DOI: 10.1136/bmj.308.6935.992.

9. Isbister GK. Delayed asystolic cardiac arrest after diltiazem overdose: resuscitation with high dose intravenous calcium. Emrg Med J 2002;19(4):355-357. DOI: 10.1136/emj.19.4.355.

10. Yuan TH, Kerns II WP, Tomaszewski CA, Ford MD, Klinc JA. Insulin glucose as adjunctive therapy for severe calcium channel antagonist poisoning. Clin Toxicol 1999;37(4):463-474. DOI: 10.1081/CLT100102437.

11. Durward A, Guerguerian AM, Lefebvre M, Shemie SD. Massive diltiazem overdose treated with extracorporeal membrane oxygenation. Pediatr Crit Care Med 2003;4(3):372-376. DOI: 10.1097/01.PCC.0000074273.50306.F5.

12. Ezidiegwu C, Spektor Z, Nasr MR, Kelly KC, Rosales LG. A case report on the role of plasma exchange in the management of a massive amlodipine besylate intoxication. Ther Apher Dial 2008;12(2):180-184. DOI: 10.1111/j.1744-9987.2008.00567.x.

13. Daubin C, Lehoux P, Ivascau C, Tasle M, Bousta M, Lepage O, et al. Extracorporeal life support in severe drug intoxication: a retrospective cohort study of seventeen cases. Crit Car 2009;13(4):R138. DOI: 10.1186/cc8017.

14. Weinberg RL, Bouchard NC, Abrams DC, Bacchetta M, Dzierba $A L$, Burkart KM, et al. Venoarterial extracorporeal membrane oxygenation for the management of massive amlodipine overdose. Perfusion 2014;29(1):53-56. DOI: 10.1177/0267659113498807.

15. Vignesh C, Kumar M, Venkataraman R, Rajagopal S, Ramakrishnan N, Babu KA. Extracorporeal membrane oxygenation in drug overdose: a clinical case series. Indian J Crit Care Med 2018;22(2):111-115. DOI: 10.4103/ijccm.IJCCM_417_17.

16. DeWitt CR, Walksman JC. Pharmacology, pathophysiology and management of calcium channel blocker and $\beta$-blocker toxicity. Toxicol Rev 2004;23(4):223-238. DOI: 10.2165/00139709-20042304000003. 